\title{
The Menarche Journey: Embodied Connections and Disconnections
}

\author{
Niva Piran
}

After I got my first period, they [three adult women] welcomed me into womanhood. They took me out to this beautiful waterfall, a beautiful place that I had never even heard of. And they each talked to me about being a woman and they each gave me something that had been given to them by another woman, and talked about the strengths and powers that she had . . . It made me feel really special ... It's something I would really like to do for others ... In different cultures people do more for that kind of getting your period, kind of growing up whatever for girls, but our culture doesn't really recognize that. And in some ways I think they kind of 'Oh it's one more headache,' but I think it's really important to recognize that, because it is a big moment . . The ceremony made me feel more loved, like people will always be there for me.

Brenda, a 12-year-old White girl, living in a rural site in North America, in a home that vacillated between being financially strained and of middle class standing, participated in a study about the embodied life of adolescent girls (Piran 2017). In this narrative, Brenda describes a unique and meaningful welcoming ceremony conducted by three women during the month following her menarche. She highlights the positive embodying elements in this ceremony: the honoring of a big moment in her life marked by a biological transition, and feeling "special," "loved," and that "people will always be there" for her. Having gone through this ceremony, Brenda recognizes that she is situated differently from other girls and women that view menstruation as a "headache," making her motivated to conduct the same ceremony for others. Through this unique relational women-centered ceremony, taken place in a physical territory found and chosen by these women, patriarchy (and other sources of disruption to menstruating women) was marginalized. While, as we follow Brenda prospectively for the next five years, we find that she faces common challenges to owning menstruation positively in a patriarchal world, we also hear that she carries the welcoming ceremony with her, never feeling about menstruation as negatively as other girls. As this chapter 
unfolds, we return to examining particular elements in Brenda's narrative in relation to other girls at menarche.

Contrasting women's and men's experiences of inhabiting their bodies in the world in her book, The Second Sex, Simone de Beauvoir described the experience of (White, privileged) men as having “. . . direct and normal connection with the world" (de Beauvoir 1989, xxi). This chapter focuses on the experience of menarche and "connection to the world" through the lens of embodiment and the Developmental Theory of Embodiment (Piran 2017). This theory can be a productive frame for examining menarche. First, the theory centers on the social factors that shape the quality of embodied lives, all the way from 'positive body connection and comfort, embodied agency and passion, and attuned self-care' to 'disrupted body connection and discomfort, restricted agency and passion, and self-neglect or harm' (Piran 2016, 47). Second, the theory addresses both positive and disruptive social factors, thus resonating with concerns about the negative bias in the construction of menarche (and menstruation) in research (Burrows and Johnson 2005). Third, the theory, anchored in girls' and women's lived experiences, integrates a range of social factors that tend to be studied and conceptualized as separate phenomena, providing a wide lens through which to look at the intersection of body and culture at menarche.

In examining menarche in relation to "embodied connection with the world," I draw mainly from a five-year prospective interview study involving 87 interviews with 27 girls who were 9-14 in the first phase, that focused on girls' description of their embodied experiences and the social factors that shaped them (Piran 2017). The prospective lens helps clarify changes girls identify as particularly poignant for them at menarche. All girls resided in Canada during the time of the study and were from diverse social locations in terms of ethnicity and heritage, socioeconomic status, and family composition (Piran 2017). The chapter is also informed by a participatory action research with girls and boys, ages 10-18 (Piran 2001) and two retrospective life-history studies on embodied journeys with younger (ages 20-28) and older (ages 50-70) women, for a total of 84 interviews with 42 women.

The Developmental Theory of Embodiment (Piran 2017) suggests that the social experiences that shape embodiment, both facilitative and adverse factors, fall into three main categories. These include experiences in the physical domain (physical freedom vs. corseting), the mental domain of social discourses and expectations (mental freedom vs. corseting), and the social power and relational connections domain (social empowerment and relational connections vs. social disempowerment and relational disconnections). In particular, physical freedom, mental freedom, and social power and relational connections contribute to positive embodiment. In this chapter, we examine the experience of menarche narrated by girls going through puberty in these three categories, emphasizing the theme of "embodied connection to the world." 


\section{Embodied Connection and Agency \\ in the Physical Territory}

They took me out to this beautiful waterfall, a beautiful place that I had never even heard of. And they each talked to me about being a woman.

One component Brenda highlights in her menarche welcoming ceremony relates to the beautiful place in nature, new to her, and shared with her by the three women. She emphasizes again the value she places on connection to the physical environment in a later interview where she singles out a challenging nature exploration with her mother as the time she has felt best ever in her body, feeling "excited, relaxed, and really good."

Freedom of physical engagement and movement (Piran 2017) is a category of physical experiences that includes engagement in joyful physical activities and the freedom to move freely in the private and public spheresexperiences that are centrally important to connection to the physical environment and to embodied agency. However, we find that girls at menarche commonly describe a highly disruptive crisis of physical restriction to continued engagement in physical activities and to free movement across a range of physical sites. The colonization of the public sphere by men and boys (as it also intersects with other dimensions of privilege related to ethnicity/ race, ability, social class, et cetera) is accentuated once girls menstruate and gendered boundaries become less permeable. For example 13-year-old Melissa describes the experience in the following way,

[Up to age 11] we stayed outside all the time. We'd go to ponds and try to catch mice and frogs and turtles and bugs. This boy was in my class and we hung out with his older brothers ... We also played soccer and stuff . . . I would be out in the field having fun! ... In grade 5 we stopped [nature explorations] ... I spend more time with girls ... Cause when we started getting our periods, then we'd talk more about that and about who do you like. [White, middle class, rural]

The schoolyard is another arena, we find, where the gender segregation becomes clear at menarche, around age 11 , whereby boys remain physically active in the central space of the schoolyard while girls gather in the margins to talk (Edwards, Knoche, and Kumru 2001).

Concurrent with girls' expressions of protest and loss about their physical corseting, we find the glaring disappearance of narratives of fun and passion in leisure (often physical) activities, of physical agency, and of connection to the physical environment and to the co-ed non-sexualized social environment. Thirteen-year-old Lauren, for example, describes it in the following way, "The monthly thing! Hard to go camping, swimming. Guys don't have to worry about it . . . we used to play outside, fun!” The loss of the normative physical engagement in the public sphere, we find, is more 
profound among girls whose families struggle financially and who therefore cannot "buy" continued engagement in physical activities through paid organized sport activities.

The physical management of menstruation is one factor that shapes physical restriction, and girls often find that the social environment is not geared toward, attuned to, or supportive of menstruating bodies-a form of 'introduction' to living in women's bodies. Rather, different barriers are erected to their continued physical engagement with agency in the world. In our prospective study (Piran 2017) we find that, while some girls continue their engagement in physical activities with support from significant adults, most girls change to a more sedentary life style (Kimm et al. 2002).

Girls in our study relied on commercial menstruation supplies. Commercial supplies are costly, and trying to find cheaper alternatives may lead to greater discomfort, as Kyra describes,

I was afraid to use tampons, but my friend had this pool party and I had my period and I was like, 'Ok, I am doing it' . . . But I use 'no name' and I thought it got stuck inside, and I was crying. 'No name' are not as good as Kotex, but I love Kotex cause they are easy.

Research around the world highlights challenges in accessing menstrual supplies within the context of poverty (for example, Crichton et al. 2013; Goldberg 2017). A meta-analysis of 138 studies conducted in India described multiple restrictions to girls' participation in the public sphere during menstruation, with a quarter of the girls missing school related to "menstrual hygiene management" (Van Eijk et al. 2016).

However, physical corseting during menstruation relates not only to barriers in accessing menstrual supplies, but also to the pervasive stigma of menstruation; as long as taboos and stigma surround menstruation, menstruating girls and women will not feel supported or safe in participating in the physical and social world (Bobel 2018). Even girls at menarche who have access to a range of commercial menstrual products commonly avoid physical activities they have previously cherished, such as swimming or camping, in order to avoid being found out as menstruating Lauren, an avid camper, for example explained that, "Camping would be fun. But I don't want to get my period during camping. Boys could not shower for days and they'd be fine. They don't have to worry about their periods so it is easier for them" [White, middle class, urban]. Hence, propagated messages by commercial manufacturer of menstrual supplies regarding the "successful" management and hiding of menstruation, serve to reinforce an oppressive status quo.

Access to physical territories reflects processes of social privilege, colonization, disenfranchisements, and oppression, bolstered by associated prejudicial belief systems, policies, and laws. Such processes impose physical restrictions and regulate the spaces where girls can engage post-menarche and during 
menstruation, with formal or informal policing. In our study, we found consistent peer, and at times parental, policing of girls' compliance with restricted physical activities post-menarche in line with 'femininity' discourses. These discourses are summarized aptly by 11-year-old Jackie, "Because girls, they are like, 'I'm a porcelain doll, I'm just gonna sit here and be perfect" [Aboriginal, working class, urban]. Girls who try to continue to play with boys physical games in the schoolyard, are at the risk of being ostracized.

Clothing norms post-menarche can reinforce processes of space colonization. In different Western countries, peer-enforced clothing norms for girls around menarche involve a shift to wearing 'feminine' tight and exposing clothing, which restrict physical action, as 12 -year-old Madison described "I had a skirt on that was short and I jumped over a fence and the boys started laughing, like: what? They saw my skirt come up, I walked away. There are things girls are not supposed to do" [Aboriginal, working class, urban]. As girls cease their engagement in a range of physical activities, their physical skills and agency become compromised.

The expectation to clad the body of girls post-menarche in heavy layers of clothing comprises another challenge to physical engagement with the world. In Canada, we found a struggle around adaptation of public spaces to the needs of girls at menarche whose norms of attire differ from prevalent norms. For example, the lack of availability of women-only swim time at a local pool, prevented 13-year-old Hazel, who is a practicing Muslim and has started to wear a hijab upon her menarche, the opportunity to continue and pursue her favorite physical activity, swimming, "I love swimming so much. I mean, I haven't gone to swim in a while because I can't take the hijab off in a public pool" [Middle East heritage, working class, urban]. The physical restrictions on occupying particular spaces while menstruating or of engaging in varied activities while menstruating exist around the world (Van Eijk et al. 2016).

Still within the physical domain, menarche accentuates not only restrictions to engagement with the physical environment, but also the physical vulnerability of girls, as 12-year-old Madison describes, "I just got my period and it made me feel cautious. Just in case I ever turn stupid and do something. I don't want to get pregnant and be stuck with the baby . . . So it made me feel cautious" [Aboriginal, working class, urban].

Girls at puberty are exposed to a dramatic increase in sexual harassment and sexual violations (Piran 2017; "Sexual Violence: Facts at a Glance" 2012), and, in some cases, to early and forced marriages (Field and Ambrus 2008). Living in a rape culture (Buchwald, Fletcher, and Roth 1993), girls' awareness that sexual activity can, once they start to menstruate, lead to pregnancy, and that it is them who will endure the consequences, enhances the experience of vulnerability associated with the body, as Alice describes, "You need a lot more precautions in Grade 7 because of alcohol and drugs and sex with boys." Girls are entrusted with the responsibility of preventing pregnancy without the social conditions of safety, and, moreover, the lack of sanctioning and guidance in practicing their desires with self-attunement and 
boundaries (Piran 2017; Tolman 2002). Being socially abandoned to manage menstruation and sexuality with little support, guidance, or protection, it is not surprising the girls sometimes make potentially harmful decisions, such as having intercourse prior to menarche, 12-year-old Kyra describes,

Girls start having sex in grade 5 because they don't have their period and they can't get pregnant. I think some of them do it because their boyfriends wanted to have sex and they think, 'what the hell, why not do it.'

Overall, then, overlapping experiences at menarche contribute to disrupted embodied connection and agency in the physical territory. As many girls' temporary freedom of engagement in the physical environment alongside boys ends at menarche and gender boundaries becomes less permeable, embodied joy and agency, as well as positive connection to the physical environment and to one's body-described by Brenda at the beginning of this section-are compromised.

\section{Mental Corseting of the Embodied Self}

And they each talked to me about being a woman and they each gave me something that had been given to them by another woman, and talked about the strengths and powers that she had... It made me feel really special.

Here Brenda highlights the value for her, as a girl who has just gone through menarche, of hearing the women speak of engaging in the world with strength and power while inhabiting women's bodies. Engaging with the world powerfully, meaningfully, and passionately by diverse women requires the maintenance of a critical stance toward constraining social discourses that regulate embodied lives of individuals of different social locations and that aim to maintain the social status quo (Piran 2017). Regarding femininity, our research suggests two sets of discourses that constrain the way girls and women inhabit their bodies and engage with the world and that exert accentuated pressures at menarche. We further find that menstruation-related discourses can be contextualized within other gender-related discourses narrated by girls at menarche.

The first set of constraining gender-related discourses, is appearance-related, entitled "body as a deficient object" (Piran 2017), and marks a woman's body both as an object of gaze, an adverse experience highlighted by Objectification Theory (Fredrickson and Roberts 1997), and as an inherently physically deficient site (Bordo 1993). While the discourse of objectification is narrated by girls prior to the onset of puberty, our prospective qualitative interviews reveal the emergence of new narratives, around the time of menarche, that mark multiple aspect of one's body as deficient, such as: "my hair needs to be tamed in the mornings, like a forest, a rat's nest," "I hate armpit hair, it's disgusting," "I hate the hair on my legs," 
"my stomach has like a bump," "my eyebrows are screwed up," "I'm not pretty without make up," "I am fat, I want to be small," and "it's weird to think about girls sweating, pretty girls do not sweat, I try not to." The internalized deficiency discourse compels girls at puberty to control and "repair" multiple aspects of their natural body, such as: weight, shape, hair (body and scalp), skin color, and facial features.

At menarche, menstruation compounds the experience of the body as a deficient object in its natural state (Roberts et al. 2002), as 13-year-old Kyra and 12-year-old Jackie described: "I hate my period, all these hormones, I am all bloated, I've got blood coming out of me everywhere, it's disgusting" [Kyra, White, working class, urban; "periods are dirty blood" [Hazel, Middle East heritage, working class, urban]. Within the context of engagement in varied body alterations, menstruation poses challenges to the wish to control and repair the body, leaving girls with the option of vigilance: being ever ready for their periods and finding strategies to hide their presence in their lives from their social world. They hold with terror the possible loss of such control and of facing the socially sanctioned response of disgust,

It happened to my friend. She was running around and all of a sudden she got this red stuff on the back of her pants, and we're like "Eeuuww". It was gross and embarrassiong. She still denies it was her period. [Jackie, Aboriginal, working class, urban]

Though this response of disgust is shared among peers, girls specifically highlight boys' negative response to menstruation, "Boys probably think "Ewww"' [Lauren; White, middle class, urban]. Thus, upon menarche, in particular, girls begin to engage with the world around them while viewing their bodies as deficient sites, experiences that inherently weaken their embodied agency in the world and direct them to channel energy into body repair.

The second set of constraining 'femininity' discourses is comportment-related and entitled woman as docile (Piran 2017). It directs girls and women to act in the world in demure and submissive ways; subvert their own needs, wishes and meaningful pursuits to that of boys and men; and avoid being too assertive, loud, dominant, needy, or simply 'too much.' One comportment-related discourse girls describe is the pressure to engage in 'feminine' (or 'girlie') activities, once they go through menarche. Menarche problematizes a 'tomboy' way of inhabiting the world: a temporary option that allowed girls to have the freedom to act in the world similar to boys without social penalties, as 12-year-old Madison describes,

Like I got my period 4 months ago, which is a big change of the body. A couple of months ago I started wearing pink and stuff. I used to wear real loose clothes, but now I wear clothes that are a bit closer to my body, tighter. People call [friend] a tomboy and they call her a man and stuff because she dresses in a 
guy clothes. But they call me and [another friend] girlie girls because we dress now a lot in the color pink. I love sports but they usually say that girly girls don't like sports. [Aboriginal, working class, urban]

A second discourse from the comportment-related 'woman as docile' cluster that girls at puberty allude to is the submissive/demure discourse that reigns-in girls' voices, assertiveness, and anger (Piran 2017). Brenda, for example, describes that, "there is, like, a kind of thing for girls to be really nice" (Brown 2003), and contrasts, at age 12, being "nice" with being "a bitch" or "a butch," suggesting, for example, that "A butch speaks her mind. They are more comfortable with themselves." At menarche, the "PMS" discourse joins the "bitch" discourse and is contrasted with being compliant, nice, controlled, and subservient. At age 13, Kyra, for example, describes many sources of anger in her life. Having experienced lack of safety and fear from a male family member, his labeling of her anger and boundary-setting as 'PMS' and her 'bitch' self-labeling serve to problematize her body rather than challenge the sources of her anger in her home environment. Though owning being a "bitch" and a "psycho" while "on PMS" liberates Kyra to stand up to her abuser, this labeling ultimately maintains the abusive status quo,

Some days you piss him off and he will flip. He's just way bigger than me and stronger, and when he yells, it scares the crap out of me. But, like period day is the day that I get pissed off. I would be in a grumpy mood and he's like, What's your problem? I'm just be like, 'Leave me alone!' and he' just be like, 'Oh, you're PMS-ing' . . . Whenever I'm getting near my period. I eat so much. Like I'm psycho. Like I'm actually insane. I am being such a bitch, but I can't stop myself. When you are on PMS then you are just a bitch.

We do not commonly hear from girls throughout puberty, including menarche, of relational connections at home or at school that support them in counteracting these discourses, a situation that likely emanates from adult women's own struggles with these discourses and the consistent impact of these discourses on peer norms.

Overall we find in our prospective study (Piran 2017), the tightening of 'femininity'-related discourses at menarche, both 'woman's body as deficient' and 'woman as docile,' clarify the way girls at menarche are expected to shift considerably the way they inhabit their bodies and comply with inequitable gendered relations (de Beauvoir 1989). At menarche, menstruation-related discourses, such as: disgusting, dirty, and PMS, weave into 'femininity' discourses and intensify their impact. Without relational connections that counteract 'femininity' stereotypes and their intersection with 'menstruation' discourses, as molds of femininity tighten, girls' connection to their bodies, their self-attunement, subjective immersion in passionate pursuits, and embodied agency, are affected adversely, disrupting embodiment. 


\section{Embodied (In)EQUity in Relational Communities}

It's something I would really like to do for others . . . In different cultures people do more for that kind of getting your period, kind of growing up whatever for girls, but our culture doesn't really recognize that. And in some ways I think they kind of 'Oh it's one more headache,' but I think it's really important to recognize that, because it is a big moment . . . The ceremony made me feel more loved, like people will always be there for me.

Here Brenda alludes to the value of a community embracing menarche as an important landmark of growing up, and the tightening of relational connections that ensues. While most girls' experiences were starkly different from Brenda's, her observation of a close link between the response of the community and individual girls' experiences of menarche is apt; extending this thought, a more constructive experience of menarche relates to community transformations. Experiences of embodied equity in relational connections enhance experiences of embodied pride and self-worth, and, hence, positive embodiment; in contrast, exposure to prejudicial treatment and relational disconnections from desired communities disrupt embodiment (Piran 2017).

Reading the cultural landscape, in particular the stigma of menstruation and the lack of community embracement, or at least support, girls at menarche experience first-hand the demotion in social power associated with inhabiting a 'young woman's' body at the cusp of puberty. The intensity of the negative stigma attached to menstruation (Fahs 2011; Ginsburg 1996; Roberts et al. 2002) is matched by the intensity of terror as vividly described by premenstrual girls in the year preceding menarche from 'being found' menstruating, as ten-year-old Emma describes, "It's so scary getting your period, starting it and you won't be prepared, and you don't want anyone to know, you don't know what they'll think about you. Guys probably think 'Ew'" [White, middle class, rural]. Girls often make elaborate plans about how to be prepared for menarche, as ten-year-old Alice describes, "I am worried that if I have it [period] at school my teacher wouldn't have a tampon, but they have them upstairs in the girls' bathroom. I am always going to carry 25 cents with me. We are all worried" [Aboriginal, middle class, urban]. The stigma is as strong in all-girls schools, as 13-year-old Hazel describes, "I actually noticed that a lot of my friends in Islamic school were ashamed that they had it. It was this stigma thing." Hazel also raised the stigma associated with being barred from participation in prayer time during menstruation. The physical segregation of menstruating women from community, religious, and household activities has been reported around the world (Dunnavant and Roberts 2013; Van Eijk et al. 2016).

As girls internalize the stigma and comply with the social etiquette of not making the period a material presence in the social environment (Ginsburg 1996), a disempowering process, they experience further embodied demotion 
by the lack of social support, accommodation, or attunement to their needs in managing menstruation. Girls describe the school environment as not respectful to the needs of their maturing bodies: they face blocked access to washrooms during class time, lack of privacy associated with requests to access menstrual supplies, and empty tampon machines in washrooms, as Alice describes at the age of 12 ,

Sometimes we need to go to the bathrooms, and the teacher is like, 'Why do you have to go to the bathroom'? . . . and if we go in the hallway to the locker people can see that, but we are not allowed to carry a purse to class. We opened up the tampon machine in the washroom. There are no tampons in it. They won't refill it.

School educational programs about puberty, while replete with diagrams and scientific explanations and conducted often in co-ed forums, do not address actual challenges in managing menstruation, as described earlier in the chapter.

Poverty challenges further the management of menstruation in all regions of the world (Van Eijk et al. 2016). In western countries that rely on manufactured sanitary supplies, the actual cost of menstrual supplies for people who live in poverty can be higher due to the difficulty of putting forward the money needed for a bulk purchase, or due to challenges to accessing transportation to larger stores and needing to rely on small stores in their own communities (Weiss-Wolf 2017). In most states in the US, there is sales tax on menstruation supplies, as they are not classified as "basic necessity" by these states (Weiss-Wolf 2017). This societal disavowal of a biological experience affecting half of the adolescent and adult populations relates centrally to social justice, and reflects the devaluation and disenfranchisement of adolescent girls, women, and their bodies.

As girls try to break their isolation around menstruation, they risk silencing at all levels of the social environment as, for example, Kyra and Hazel describe: "I was sitting in the car and I was asking my mom questions about tampons because I just started. And She's like, If you want to talk about tampons, you come to me privately. So I just asked my friend"; "Hazel, don't talk about it at the dinner table." Shame and isolation pervade even the closest girls' friendship networks during the first year post-menarche, as Lauren describes the situation at age 13, "Girls who have their periods at school, hide and change their shorts in the bathroom because it is embarrassing, and there are worries about embarrassing incidents, like blood soaking through" [White, middle class, urban]. The stigma and associated silencing therefor disrupt connections between girls, their mothers, and their friends (Stubbs and Costos 2004).

Girls use different strategies to reduce isolation and shame and restore some social power. They sometimes take a risk by reaching out to friends, as Lauren describes, “The first time you talk with other girls about that, you're 
putting yourself out there and you could have someone go, ew." A second approach to restoring social power and connections, utilized by girls who have been supported in learning how to manage menstruation, is to become a resource for other girls. Such experiences of functionality in relation to menstruation, such as confronting as a group of boys who have teased them about menstruation.

Girls' own initiatives to deal with stigma, isolation, and disempowerment, cannot replace the need for systemic transformations involving different levels of the social environment, from immediate relational connections to larger social organizations (Stubbs 2008). Having the experience of being part of at least one social system where equity is practiced (as Brenda's experience reflects) transmits embodied worth and therefore contributes to positive embodiment. It can further protect against the adverse impact of broader societal prejudices (Piran 2017).

Overall, within patriarchy and related ideological systems, the stigma, silencing, and lack of social and systemic support, marks menarche as a biological event associated with embodied demotion in social power and ruptures in relational networks and communities. Exposure to communities of equity, at any level of the social environment, can have an important protective impact and preserve important relational connections and embodied worth. Further, even within the context of social inequity, community connections among women around the experience of menstruation can have a positive, protective impact. For example, Dunnavant and Roberts (2013) found that women who followed restrictive religious rituals involving menstruation identified the heightened sense of community with other women as a positive aspect of their menstrual cycle; this element was lacking among non-religious women. The present study with girls at menarche and research with adult women therefore suggest positive possibilities inherent in providing girls and women with all-women spaces where connections can be forged around embodied experiences, comprising also fertile ground for the development of subversive knowledge and related activism. In contrast, the shamed isolation commonly reinforced by the dictates of silence and private management immobilizes girls and women from inhabiting their menstruating bodies with passion, agency, pride, and comfort.

In conclusion, the chapter suggests that menarche is associated with connections and disconnections in the life of girls in three domains of experiences that should be considered concurrently in order to understand girls' experiences of embodiment. While connection to the physical territory, established through engaging freely, actively, and safely in the public sphere, enhances embodied agency and positive connection to the body, girls commonly describe, protest, and grieve restrictions to such freedom at menarche; this change serves to reinforce boys' and men's colonization of the physical sphere once gender boundaries become less permeable. This disrupted connection to physical territories may not emerge as central in adult women's retrospective accounts of menarche, since restrictions to 
joyful physical engagement with the world becomes 'normative' postpuberty in western and non-western countries. Girls' experienced abandonment by adults and varied social systems (for example, schools, sports organizations) regarding their wish to stay engaged physically while menstruating-expressed, for example, through the lack of supportive guidance, forced secrecy, and infringed sexual safety-clarifies the colonization of their bodies and geographical territories by boys and men.

Examining the domain of social discourses at menarche suggests that the physical restrictions in the life of girls are reinforced by pressures to embody constraining discourses of 'femininity', in particular, the woman's body as a deficient object and women as docile (Piran 2017). Menstruation-related discourses, such as menstrual bleeding as gross and menstruating women as bitchy or "on PMS," compound the deprecation of the natural body of girls and women and the problematizing of angry, assertive, or other 'unruly' behaviors. Girls at menarche are therefore under accentuated pressure to comply with living in altered and docile bodies, leading to girls' disrupted connections with their pre-menarche embodied selves.

Further disrupting embodiment is the demotion of menstruation and its association with stigma, silencing, and societal disavowal, to which girls are introduced at menarche. These social processes disrupt connections to social networks and communities, including among girls and women. Positive embodiment at menarche relates to the availability of relational connections and norms that can counteract adverse social experiences, and, ultimately, requires social transformations in all three domains.

\section{REFERENCES}

de Beauvoir, Simone. 1989. The Second Sex. Translated by H. M. Parshley. New York: Random House.

Bobel, Chris. 2018. "Menstruators Need More Than Something to Bleed on, They also Need Information and Support." WASHfunders: Blog. http://washfunders. $\mathrm{org} / \mathrm{blog} / \mathrm{menstruators-need-more-than-something-to-bleed-on-they-also-need-}$ information-and-support/.

Bordo, Susan. 1993. Unbearable Weight: Feminism, Western Culture, and the Body. Berkeley: University of California Press.

Brown, Lyn Mikel. 2003. Girlfighting: Betrayal and Rejection among Girls. New York, NY: New York University Press.

Buchwald, Emilie, Pamela Fletcher, and Martha Roth. 1993. Transforming a Rape Culture. Minneapolis, MN: Milkweed Editions.

Burrows, Anne, and Sally Johnson. 2005. "Girls' Experiences of Menarche and Menstruation." Journal of Reproductive and Infant Psychology 23: 235-49. https://doi.org/10.1080/02646830500165846.

Crichton, Joanna, Jerry Okal, Caroline W. Kabiru, and Eliya M. Zulu. 2013. "Emotional and Psychosocial Aspects of Menstrual Poverty in Resource-Poor Settings: A Qualitative Study of the Experiences of Adolescent Girls in an Informal Settlement in Nairobi." Health Care for Women International 34: 891-916. https://doi.org/10.1080/07399332.2012.740112. 
Dunnavant, Nicki C., and Tomi-Ann Roberts. 2013. "Restriction and Renewal, Pollution and Power, Constraint and Community: The Paradoxes of Religious Women's Experiences of Menstruation." Sex Roles 68: 121-31. https://doi. org/10.1007/s11199-012-0132-8.

Edwards, Carolyn P., Lisa Knoche, and Asiye Kumru. 2001. "Play Patterns and Gender." In Encyclopedia of Women and Gender, edited by Judith Worrell, 809-16. San Diego: Academic Press.

Van Eijk, Anna Maria., M. Sivakami, Mamita Bora Thakhar, Ashley Bauman, Kayla F. Laserson, Susanne Coates, and Penelope A. Phillips-Howard. 2016. "Menstrual Hygiene Management among Adolescent Girls in India: A Systematic Review and Meta-Analysis." British Medical Journal Open. https://www.ncbi.nlm.nih.gov/ pmc/articles/PMC4785312/.

Fahs, Breanne. 2011. "Sex during Menstruation: Race, Sexual Identity, and Women's Accounts of Pleasure and Disgust." Feminism \& Psychology 21: 155-78. https:// doi.org/10.1177/0959353510396674.

Field, Erica, and Attila Ambrus. 2008. "Early Marriage, Age of Menarche, and Female Schooling Attainment in Bangladesh." Journal of Political Economy 116: 881-930. https://doi.org/10.1086/593333.

Fredrickson, Barbara L., and Tomi-Ann, Roberts. 1997. "Objectification Theory: Toward Understanding Women's Lived Experiences and Mental Health Risks." Psychology of Women Quarterly 21 (2): 173-206.

Ginsburg, Ruth. 1996. “Don't Tell, Dear': The Material Culture of Tampons and Napkins." Journal of Material Culture 1: 365-75. https://doi.org/10. $1177 / 135918359600100305$.

Goldberg, Eleanor. 2017. "Why Many Native American Girls Skip School When They Have Their Periods." Huffington Post, August 25. http://www.huffingtonpost.ca/ entry/what-its-like-to-be-a-teen-in-the-us-who-cant-affordtampons_us_597216dde4b09e5f6cceddfb.

Kimm, Sue Y. S., Nancy W. Glynn, Andrea M. Kriska, Bruce A. Barton, Shari S. Kronsberg, Stephen R. Daniels, Patricia B. Crawford, Zak I. Sabry, and Kiang Liu. 2002. "Decline in Physical Activity in Black Girls and White Girls during Adolescence." New England Journal of Medicine 347 (10): 709-15. https://doi. org/10.1056/nejmoa003277.

Piran, Niva. 2001. "Re-Inhabiting the Body from the Inside Out: Girls Transform Their School Environment." In From Subjects to Subjectivities: A Handbook of Interpretive and Participatory Methods, edited by Deborah L. Tolman and Mary Brydon-Miller, 218-38. New York: New York University Press.

- 2016. "Embodied Possibilities and Disruptions: The Emergence of the Experience of Embodiment Construct from Qualitative Studies with Girls and Women." Body Image 18: 43-60. https://doi.org/10.1016/j. bodyim.2016.04.007.

- 2017. Journeys of Embodiment at the Intersection of Body and Culture: The Developmental Theory of Embodiment. San Diego, CA: Elsevier.

Roberts, Tomi-Ann., Jamie L. Goldenberg, Cathleen Power, and Tom Pyszczynski. 2002. "'Feminine Protection': The Effects of Menstruation on Attitudes towards Women." Psychology of Women Quarterly 26: 131-39. https://doi. org/10.1111/1471-6402.00051. 
"Sexual Violence: Facts at a Glance." 2012. Division of Violence Prevention, National Center for Injury Prevention and Control, Center for Disease Control, US. https://www.cdc.gov/ViolencePrevention/pdf/SV-DataSheet-a.pdf.

Stubbs, Margaret L. 2008. "Cultural Perceptions and Practices Around Menarche and Adolescent Menstruation in the United States." Annals of the New York Academy of Sciences 1135: 58-66. https://doi.org/10.1196/annals.1429.008.

Stubbs, Margaret L., and Daryl Costos. 2004. "Negative Attitudes towards Menstruation: Implications for Disconnection within Girls and between Women." Women \& Therapy 27: 37-54. https://doi.org/10.1300/j015v27n03_04.

Tolman, Deborah L. 2002. Dilemmas of Desire: Teenage Girls Talk about Sexuality. Cambridge, MA: Harvard University Press.

Weiss-Wolf, Jennifer. 2017. Periods Gone Public: Taking a Stand for Menstrual Equity. New York: Arcade Publishing.

Open Access This chapter is licensed under the terms of the Creative Commons Attribution 4.0 International License (http://creativecommons.org/licenses/ by $/ 4.0 /$ ), which permits use, sharing, adaptation, distribution and reproduction in any medium or format, as long as you give appropriate credit to the original author(s) and the source, provide a link to the Creative Commons license and indicate if changes were made.

The images or other third party material in this chapter are included in the chapter's Creative Commons license, unless indicated otherwise in a credit line to the material. If material is not included in the chapter's Creative Commons license and your intended use is not permitted by statutory regulation or exceeds the permitted use, you will need to obtain permission directly from the copyright holder.

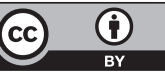

